\title{
SCIDOC
}

\author{
International Journal of Dentistry and Oral Science (IJDOS) \\ ISSN: 2377-8075
}

\section{Occurrence of Periodontitis and Associated Factors among Young Adults}

Research Article

Tan Yet Wen, Akram Hassan

School of Dental Sciences, Universiti Sains Malaysia, Kubang Kerian, Kelantan, Malaysia.

\section{Abstract}

Objective: The present study was conducted to assess the occurrence of periodontitis and associated factors among young adults attending Hospital Universiti Sains Malaysia Dental Clinic (HUSM).

Materials and Methods: This study involved the retrieval of secondary data from the patient's dental record of 99 patients from 1st January 2017 until 31st December 2017 at HUSM Dental Clinic. The Basic Periodontal Examination (BPE) score of the patients during dental visit was recorded. Patients' personal data including sociodemographic data (age, sex, ethnicity, education level and working status), smoking status and systemic disease were retrieved to find out the association with periodontitis. The data was entered and analyzed using Statistical Package for Social Science (SPSS) version 24.0 software.

Results: The results showed that the prevalence of periodontitis among young adults was $17.2 \%$ with minimum age of 21 and mean age of 28.53. Correlation value of age and periodontitis was 0.206 . There was an association between smoking and periodontitis with a p-value of 0.044 . Sex, ethnicity, education level, working status and systemic disease were found significantly not related with periodontitis with a p-value $>0.05$ respectively.

Conclusion: The prevalence of periodontitis among young adults was $17.2 \%$ and it was associated with age and smoking.

Keywords: Periodontitis; Young Adults; Age; Smoking.

\section{Introduction}

Periodontal disease is one of the two major dental diseases which have high prevalence rates worldwide, the other being caries [1].It can be mainly classified into two types; gingivitis and periodontitis. Gingivitis is the gingival inflammation which is reversible and it is not associated with loss of attachment or bone loss [2]. When the inflammation involves the tooth supporting periodontiumloss, it is term periodontitis where it is characterized by clinical attachment loss due to destruction of the periodontal ligament and loss of adjacent supporting bone [3].

In United States, attention were given to the periodontal health of the nations, a study conducted showed $47 \%$ of adults had periodontitisand $47 \%$ of adults had the similar problems shown in a three-year study conducted in the following year [4]. In Sri Lanka, the periodontal disease status for ages 35-44 years and 65-74 years with periodontal disease of all severity were $89.9 \%$ and $98.1 \%$ respectively. $82.23 \%$ of adults in France were found to have peri- odontal pocket, with $10.21 \%$ was greater than $5 \mathrm{~mm}$ [5]. In Malaysia, oral health survey was carried out in 1990, 2000 and 2010 with the results of $92.8 \%, 90.2 \%$, and $94 \%$ of dentate adults reported to have periodontal diseases respectively; and to look into details, severe periodontal disease increased from 6\% in 1990 to $18.2 \%$ in 2010 [6].

Age showed a positive association with periodontitis with increasing prevalence as the age increases, showing $8.2 \%$ difference in 30 years of age difference [5]. Smoking were one of the two major risk factors of periodontitis, other being diabetes [7]. Smokers were significantly proved to have more pockets $\geq 4 \mathrm{~mm}$ than nonsmokers [8].

At present, there is high prevalence of periodontal condition exists in the adult which needed attention to arrest the progression of disease, preserving the dentition in the state of health and to prevent recurrence of periodontitis [9]. Usually, epidemiological studies are primarily concentrated on adolescents, adults and el-

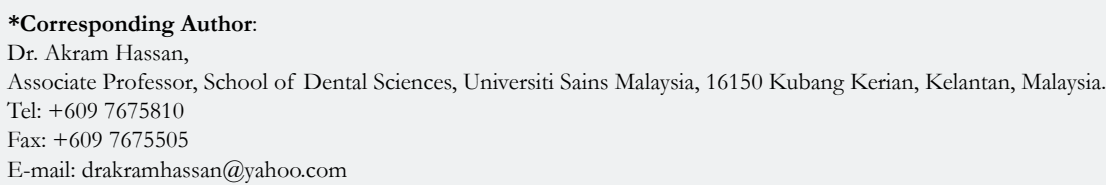

Copyright: Akram Hassan ${ }^{\circ}$ 2020. This is an open-access article distributed under the terms of the Creative Commons Attribution License, which permits unrestricted use, distribution and reproduction in any medium, provided the original author and source are credited. 
derly population. Unfortunately, no information is available for the young adults. The plausible reason for this lack of information comes from the fact that early studies presented results which suggested little or no periodontal destruction before the age of 30 years.

Therefore, this study was conducted to determine to prevalence of periodontitis in young adults and find its association with their sociodemographic background.

\section{Methodology}

This was a cross sectional study that involved secondary data collection of the patients who visited HUSM Dental Clinic for dental treatment. The source population comprised the dental records of adult patient age range from 18 to 34 years old who attended HUSM Dental Clinic from 1st January 2017 until 31 ${ }^{\text {st }}$ December 2017. From dental records, patient's sociodemographic data (age, sex, ethnicity, education level and working status), smoking status, systemic disease and BPE score were obtained and filled in.

\section{Sample Size Estimation}

The parameter under interest of this study was single proportion, which was the occurrence of periodontitis, the sample size was calculated using the formula:

$n=\frac{1.96^{2} \times P(1-P)}{\Delta^{2}}$

Anticipated population proportion $(\mathrm{P})=40.63 \%(0.40)$

Level of significance $=5 \%(0.05)$

Absolute precision $= \pm 10 \%$

So, the expected minimum sample size required was 93. A dropout of $10 \%$ was included, therefore, the sample needed for collection of data was 103 .

\section{Sampling Method}

The sampling method of this study was systemic sampling. All dental records of adult patient age range from 18 to 34 years old HUSM Dental Clinic were selected and screened using inclusion and exclusion criteria. Selected records were numbered from one (1) to $\mathrm{N}$ (N was the total selected records). Sampling interval (k) was determined by using the formula,

sampling interval, $\mathrm{k}^{\text {th }} \frac{\mathrm{N} \text { (total selected records })}{\mathrm{n}(\text { sample size })}$

A number between one and $\mathrm{k}^{\text {th }}$ was selected randomly (random start). Then, every kth dental records was selected reaching sample size.

\section{Proposed Data Analysis}

Data was entered and analyzed using Statistical Package for Social Science (SPSS) version 24.0 software. For descriptive analysis, numerical data were presented using mean (SD) or median (IQR) depending on their normality distribution and categorical data were presented using frequency (\%). For assessing the factor associated with periodontitis, linear regression was used and $\mathrm{p}$-value was set at 0.05 for numerical and chi-square used for categorical variables.

Ethical clearence was obtained from the Research Ethics and Committee (Human), Universiti Sains Malaysia (USM/JEPeM). All information was kept confidential and only accessible to researchers and only group information was reported and published.

\section{Results}

Table 1 showed descriptive data of sociodemographic characteristics and smoking status of study subjects. The mean age of subjects was 26.39. More than half of the subjects comprisedfemales (55.6\%). $84 \%$ of the subjects were Malays. More than $60 \%$ of the respondents had completed tertiary education. $52.5 \%$ of the subjects were currently not working. $86.9 \%$ of the subjects were non-smokers.

Table 2 showed the descriptive characteristic of oral and general health status. $82.8 \%$ of the subjects had a basic periodontal examination (BPE) of $2.84 .8 \%$ of the subjects had no known medical illnesses.

Table 3 showed the periodontal condition of study subjects. More than $82 \%$ of the subjects did not have periodontitis.

Table 4 showed the descriptive characteristics of periodontal condition in patients with periodontitis. The minimum age of the patients with periodontitis was 21 years and the mean age was 28.53. Table 5 showed the association between periodontitis and age of study subjects. The Pearson correlation of 0.206 showed that age and periodontitis were weakly associated.

Table 6 showed the factors associated with periodontitis. Of all the factors, only smoking was significantly related with periodontitis with a p-value of 0.044 . Smokers had almost three times greater probability of having established periodontitis compared to non-smokers.

\section{Discussion}

The prevalence of periodontitis among young adults attending HUSM Dental Clinic was reported to be $17.2 \%$. Similarly, the study that was carried out in Brazil by Susin et al. (2005) reported that $17.4 \%$ of young adults had severe form of periodontitis with probing depth $\geq 5 \mathrm{~mm}[10]$. However, a direct comparison of the present results with previous surveys performed was not feasible because these studies were either based in the CPITN methodology [11] or used specific samples. According to the study conducted, age and periodontitis were weakly correlated, with a Pearson correlation value of 0.206 . This result matched the previous studies stating periodontal disease increases in severity in older age groups [12]. Another study showed a similar weak correlation of age and periodontitis, with a correlation value of 0.251 , meaning that the severity of periodontal disease increases with age [11]. In the study conducted, smokers had almost 3 times greater probabilities than non-smokers of having established periodontitis. Similar result was reported from another study conducted showed patients with moderate to advanced periodontitis who were referred to a periodontal practice had 2.6 times the odds 
Table 1. Descriptive Data of Sociodemographic Characteristics and Smoking Status of Study Subjects (N=99).

\begin{tabular}{|c|c|c|}
\hline Variables & Mean (SD) & Frequency (Percentage, \%) \\
\hline Age & $26.39(4.746)$ & - \\
\hline Sex & & $44(44.4)$ \\
\hline Male & - & $55(55.6)$ \\
\hline Female & - & $84(84.8)$ \\
\hline Ethnicity & & $10(10.1)$ \\
\hline Malay & - & $5(5.1)$ \\
\hline Chinese & - & $1(1.0)$ \\
\hline Indian & - & $37(37.4)$ \\
\hline Education Level & & $61(61.6)$ \\
\hline No formal education & - & \\
\hline Secondary education & - & $47(47.5)$ \\
\hline Tertiary education & - & $52(52.5)$ \\
\hline Working Status & & \\
\hline Yes & - & $13(13.1)$ \\
\hline No & - & $86(86.9)$ \\
\hline Smoking Status & & \\
\hline Yes & - & \\
\hline No & - & \\
\hline
\end{tabular}

Table 2. Descriptive Characteristic of Oral and General Health Status (N=99).

\begin{tabular}{|c|c|}
\hline Variables & Frequency (Percentage, \%) \\
\hline \multicolumn{2}{|c|}{ Basic Periodontal Examination (BPE) Score } \\
\hline 2 and below & $82(82.8)$ \\
\hline 3 and $3 *$ & $12(12.1)$ \\
\hline 4 and $4^{*}$ & $5(5.1)$ \\
\hline \multicolumn{2}{|l|}{ Medical Illness } \\
\hline Yes & $15(15.2)$ \\
\hline No & $84(84.8)$ \\
\hline \multicolumn{2}{|l|}{ Types of Medical Illness } \\
\hline Allergic rhinitis & $1(1.0)$ \\
\hline Asthma & $3(3.0)$ \\
\hline Bipolar type 2 & $1(1.0)$ \\
\hline Brugada Syndrome & $1(1.0)$ \\
\hline Diabetes Mellitus & $2(2.0)$ \\
\hline Gastritis & $1(1.0)$ \\
\hline Hyperlipidemia & $1(1.0)$ \\
\hline Hypertension & $1(1.0)$ \\
\hline Myocardial Infarction & $1(1.0)$ \\
\hline Rheumatoid heart disease & $1(1.0)$ \\
\hline Sinusitis & $1(1.0)$ \\
\hline Thoracolumbar Scoliosis & $1(1.0)$ \\
\hline
\end{tabular}

*Furcation involvement

of a smoking history compared to patients in the general practice who had no history of periodontitis [13]. Such an increase in the risk of periodontitis could be due to the effect of tobacco on the immune system by inhibiting chemotactic and phagocytic functions of polymorphonuclear leukocytes, decreasing antibody production and predisposing gingival tissues to infections [14]. Results from the first United States National Health and Nutrition Examination Survey (NHANES I) demonstrated that, after adjusting for oral hygiene and other confounding variables, they still had greater periodontal destruction than former, or never 
Table 3. Periodontal Condition of Study Subjects $(\mathrm{N}=99)$.

\begin{tabular}{|c|c|}
\hline Variables & Frequency (Percentage, \%) \\
\hline Periodontitis & \\
Yes & $17(17.2)$ \\
No & $82(82.8)$ \\
\hline
\end{tabular}

Table 4. Descriptive Characteristics of Periodontal Condition in Periodontitis Patient (n=17).

\begin{tabular}{|c|c|}
\hline Minimum Age & 21 \\
\hline Mean Age (mean / SD) & $28.53(4.230)$ \\
\hline
\end{tabular}

Table 5. Association between Periodontitis and Age of Study Subjects (N=99).

\begin{tabular}{|c|c|c|c|}
\hline Dependent Variable & Independent Variable & Pearson correlation & p-value \\
\hline Age & Periodontitis & 0.206 & 0.041 \\
\hline
\end{tabular}

Table 6. Factors Associated with Periodontitis ( $\mathrm{N}=99)$.

\begin{tabular}{|c|c|c|c|c|}
\hline Variables & Odd Ratio & Pearson Chi-Square & df & p-value \\
\hline Sex & 1.136 & 0.057 & 1 & 0.812 \\
\hline Ethnicity & - & 1.121 & 2 & 0.736 \\
\hline Education status & - & 4.873 & 1 & 0.172 \\
\hline Working Status & 1.737 & 1.06 & 1 & 0.303 \\
\hline Smoking Status & 3.854 & 4.769 & 1 & 0.044 \\
\hline Medical Illness & 3 & 3.247 & 1 & 0.128 \\
\hline
\end{tabular}

smokers [15]. This showed smokers having established periodontitis was found to be independent of other variables.

In the current study findings, it had been shown that there was little correlation between sex and periodontitis which in contrast to Shiau et al., (2010), sex exhibited a significant association with prevalence, reflecting a $9 \%$ difference between males and females (37.4\% versus $28.1 \%$, respectively) [16]. Education and working statuses had shown that there was little correlation between socioeconomic statuses and periodontitis. Conventional wisdom postulates a pathogenetic sequence with socioeconomic factors as initial step leading to health characteristics following a social gradient. The higher the social position, the better the health [17]. Periodontal diseases were more frequent and severe among individuals of low socio-economic status. However, current knowledge of socioeconomic risk factors influencing periodontal health was mainly based on cross sectional data and in such studies, when adjusted for diabetes or smoking, socioeconomic factors lost their significance in multivariate analyses supporting the findings of the current study $[18,19]$. The difference in different studies could be due to the differences in variation of educational level, where more highly-educated individuals had a stronger commitment and better knowledge of taking care of oral hygiene, compared to those of the lower educational level. Poverty could also be a factor, causing the inability to obtain medical or dental assistance. Other than that, the current study findings had shown that there was little correlation between medical illnesses and periodontitis. A review of the literature by Kinane and Chestnutt (1997) found considerable evidence to suggest that diabetes and periodontitis had a direct relationship [20]. Also, a study by Slade et al., (2000) had identified edentulism and periodontal disease as two oral conditions associated with an increased systemic inflammatory response within the US population [21]. However, severe periodontal disease, which occurs in approximately $14 \%$ of the US adult population (National Institute of Dental Research, 1987), was rarely considered in the medical assessment of patients' systemic health status, supporting the findings of the current study.

The difference in the different studies could be due to the fact that the subjects comprises of individuals of different inclusion criteria and there could be a difference in the sample size of different studies.

\section{Conclusion}

The prevalence of periodontitis among young adults was $17.2 \%$ and it was associated with smoking and weakly associated with age.

These act as a baseline information to formulate a holistic healthcare to the patients at young age, so that there is a possibility the prevalence of periodontal disease will be lesser during adulthood.

\section{Acknowledgements}

We are grateful to the Director of Hospital Universiti Sains Malaysia for approving our access to the patient's medical record. We would also like to acknowledge Medical Record Unit for preparing us the folder that we have requested and allowed us to enter the study room for data collection purpose. Lastly, we would like to acknowledge School of Dental Sciences, USM for giving us this opportunity to conduct this research. Lastly, the authors 
would like express special thanks to Dr Mohd Zulkarnain Sinor, for his priceless guidance in statistic.

\section{References}

[1]. Petersen PE. The World Oral Health Report 2003: continuous improvement of oral health in the 21st century--the approach of the WHO Global Oral Health Programme. Community Dent Oral Epidemiol. 2003 Dec;31 Suppl 1:3-23. Pubmed PMID: 15015736.

[2]. Clerehugh V. Periodontal diseases in children and adolescents. British Dental Journal .2008; 204(8): 469-471.

[3]. Parameter on Chronic Periodontitis With Slight to Moderate Loss of Periodontal Support. J Periodontol. 2000 May;71 Suppl 5S:853-855. Pubmed PMID: 29537501

[4]. Eke PI, Dye BA, Wei L, Thornton-Evans GO, Genco RJ. CDC Periodontal Disease Surveillance workgroup: James Beck (University of North Carolina, Chapel Hill, USA), Gordon Douglass (Past President, American Academy of Periodontology), Roy Page (University of Washin. Prevalence of periodontitis in adults in the United States: 2009 and 2010. J Dent Res. 2012 Oct;91(10):914-20. Pubmed PMID: 22935673.

[5]. Bourgeois D, Bouchard P, Mattout C. Epidemiology of periodontal status in dentate adults in France, 2002-2003. J Periodontal Res. 2007 Jun;42(3):21927. Pubmed PMID: 17451541.

[6]. AzizHA. Periodontal Disease Amongst Malaysian. MyHEALTH Kementerian Kesihatan Malaysia.2014.

[7]. Genco RJ. Current view of risk factors for periodontal diseases. J Periodontol. 1996 Oct;67(10 Suppl):1041-9. Pubmed PMID: 8910821.

[8]. Linden GJ, Mullally BH. Cigarette smoking and periodontal destruction in young adults. J Periodontol. 1994 Jul;65(7):718-23. Pubmed PMID: 7608851 .

[9]. Talib NA. National Oral Health Care Plan for Malaysia 2011-2020. Oral Health Division, Ministry of Health, Malaysia: 2011;1-29.
[10]. Susin C, Valle P, Oppermann RV, Haugejorden O, Albandar JM. Occurrence and risk indicators of increased probing depth in an adult Brazilian population. J Clin Periodontol. 2005 Feb;32(2):123-9. Pubmed PMID: 15691340.

[11]. Peeran SW, Singh AJ, Alagamuthu G, Naveen Kumar PG. Periodontal status and its risk factors among young adults of the Sebha city (Libya). Dent Res J (Isfahan). 2013 Jul;10(4):533-8.Pubmed PMID: 24130592.

[12]. AlJehani YA. Risk factors of periodontal disease: review of the literature. Int J Dent. 2014;2014:182513. Pubmed PMID: 24963294.

[13]. Haber J, Kent RL. Cigarette smoking in a periodontal practice. J Periodontol. 1992 Feb;63(2):100-6. Pubmed PMID: 1552463.

[14]. MacFarlane GD, Herzberg MC, Wolff LF, Hardie NA. Refractory periodontitis associated with abnormal polymorphonuclear leukocyte phagocytosis and cigarette smoking. J Periodontol. 1992 Nov;63(11):908-13. Pubmed PMID: 1333526

[15]. Ismail AI, Burt BA, Eklund SA. Epidemiologic patterns of smoking and periodontal disease in the United States. J Am Dent Assoc. 1983 May; 106(5):617-21. Pubmed PMID: 6575080.

[16]. Shiau HJ, Reynolds MA. Sex differences in destructive periodontal disease: a systematic review. J Periodontol. 2010 Oct;81(10):1379-89. Pubmed PMID: 20450376

[17]. Marmot M, Wilkinson RG. Social determinants of health, 2ndedn. Oxford University Press.2006.

[18]. Locker D, Leake JL. Risk indicators and risk markers for periodontal disease experience in older adults living independently in Ontario, Canada. J Dent Res. 1993 Jan;72(1):9-17. Pubmed PMID: 8418114.

[19]. Borrell LN, Papapanou PN. Analytical epidemiology of periodontitis. J Clin Periodontol. 2005;32 Suppl 6:132-58. Pubmed PMID: 16128835

[20]. Kinane DF, Chestnutt IG. Relationship of diabetes to periodontitis. Current opinion in periodontology. 1997;4:29.

[21]. Slade GD, Offenbacher S, Beck JD, Heiss G, Pankow JS. Acute-phase inflammatory response to periodontal disease in the US population. J Dent Res. 2000 Jan;79(1):49-57. Pubmed PMID: 10690660. 